\title{
Kritischer Rationalismus und Einzelwissenschaften
}

\author{
Zum Einfluss des Kritischen Rationalismus auf die Grundlagendebatten \\ Hrsg. v. Eric Hilgendorf
}

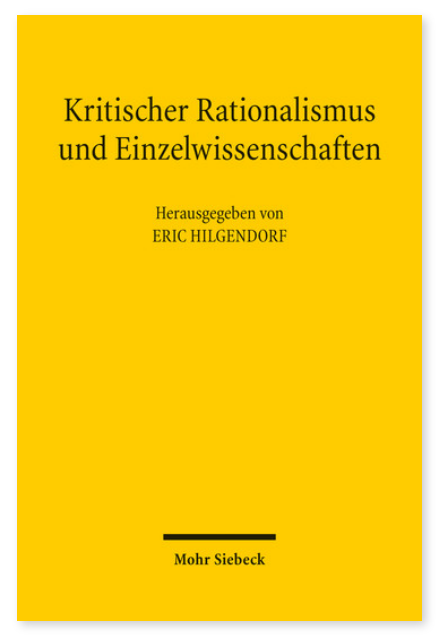

2017. VIII, 210 Seiten.

ISBN 978-3-16-155523-7

DOI 10.1628/978-3-16-155523-7

eBook PDF 59,00€

ISBN 978-3-16-155522-0

fadengeheftete Broschur 59,00€
Am 8. Februar 2016 wurde Hans Albert 95 Jahre alt. Aus diesem Anlass fand in Würzburg in Anwesenheit des Jubilars eine Tagung zum Thema »Kritischer Rationalismus und die Einzelwissenschaften« statt, in deren Rahmen der Einfluss des Kritischen Rationalismus auf die Fachdisziplinen erörtert wurde. Der Kritische Rationalismus, von Karl Popper in Auseinandersetzung mit den Denkern des Wiener (und Berliner) Kreises entworfen und in vielen Details ausgeführt, wurde maßgeblich von Hans Albert systematisiert und, weit über die Wissenschaftslehre hinausgehend, als »Entwurf einer Lebensweise« aufgefasst, welche die Einsicht in unsere eng begrenzten Erkenntnismöglichkeiten mit dem lebenszugewandten Modell von »Konstruktion und Kritik« verbindet. Alle unsere Problemlösungsversuche sind danach bloße Konstruktionen, Entwürfe, die sich in der Realität bewähren, daran aber auch scheitern können. Intellektuelle Vielfalt, Fantasie und Kritik sind Motoren jeder Verbesserung. In einer Zeit, in der selbst in Europa und den USA die Sehnsucht nach einfachen Antworten und starken Führern wieder auflebt und das Erbe der europäischen Aufklärung gefährdet erscheint wie selten zuvor, ist der kritisch-rationale Denkansatz aktueller denn je.

\section{Inhaltsübersicht}

Volker Gadenne: Die Normen der Wissenschaft: Hans Alberts Deutung der Methodologie - Herbert Keuth: Hans Albert und Karl Popper. Gemeinsamkeiten und Unterschiede - Eric Hilgendorf: Kritischer Rationalismus und Positivismus - Gert Albert: Kritischer Rationalismus und die Soziologie - Reinhard Neck: Kritischer Rationalismus und die Nationalökonomie - Armin Engländer: Kritischer Rationalismus und die Jurisprudenz - Evelyn Gröbl-Steinbach Schuster: Ist Kritische Rationalität eine Weltanschauung? - Franz Josef Wetz: Kritischer Rationalismus und Menschenwürde - Harald Stelzer: Brückenprinzipien Hans-Joachim Petsch: Das Immunsystem der Theologie Anhang

Hans Albert: Meine Philosophischen Auffassungen (2017)

Eric Hilgendorf ist Professor für Strafrecht an der Universität Würzburg.

Jetzt bestellen:

https://mohrsiebeck.com/buch/kritischer-rationalismus-und-einzelwissenschaften-9783161555237?no_cache=1 order@mohrsiebeck.com

Telefon: $+49(0) 7071-923-17$

Telefax: $+49(0) 7071-51104$ 